\title{
Development of a new chitosan hydrogel for wound dressing
}

\author{
Maximiano P. Ribeiro, MD¹; Ana Espiga, MD²,3; Daniela Silva, MD; Patrícia Baptista, MD ; Joaquim \\ Henriques, $\mathrm{MD}^{1}$; Catarina Ferreira, $\mathrm{MD}^{1}$; Jorge C. Silva, $\mathrm{PhD}^{4}$; João P. Borges, $\mathrm{PhD}^{2}$; Eduardo Pires, $\mathrm{PhD}^{2,3}$; \\ Paula Chaves, $\mathrm{PhD}^{1}$; Ilídio J. Correia, $\mathrm{PhD}^{1}$ \\ 1. Centro de Investigação em Ciências da Saúde, Faculdade de Ciências da Saúde, Universidade da Beira Interior, Covilhã, Portugal, \\ 2. Departamento de Ciências dos Materiais and CENIMAT/13N, Faculdade de Ciências e Tecnologia, Universidade Nova de Lisboa, \\ Monte de Caparica, Portugal, \\ 3. Ceramed, Estrada do Paço do Lumiar, Campus do INETI, Lisboa, Portugal, and \\ 4. Departamento de Física, Faculdade de Ciências e Tecnologia, Universidade Nova de Lisboa, Monte de Caparica, Portugal
}

\author{
Reprint requests: \\ Dr. llídio Joaquim Correia, PhD, Centro de \\ Investigação em Ciências da Saúde, \\ Faculdade de Ciências da Saúde, \\ Universidade da Beira Interior, Av. Infante \\ D. Henrique, Covilhã, Portugal. \\ Tel: +351 275329 002; \\ Fax: 275329 099; \\ Email: icorreia@ubi.pt
}

Manuscript received: January 22, 2009

Accepted in final form: July 27, 2009

DOI:10.1111/j.1524-475X.2009.00538.x

\begin{abstract}
Wound healing is a complex process involving an integrated response by many different cell types and growth factors in order to achieve rapid restoration of skin architecture and function. The present study evaluated the applicability of a chitosan hydrogel $(\mathrm{CH})$ as a wound dressing. Scanning electron microscopy analysis was used to characterize $\mathrm{CH}$ morphology. Fibroblast cells isolated from rat skin were used to assess the cytotoxicity of the hydrogel. $\mathrm{CH}$ was able to promote cell adhesion and proliferation. Cell viability studies showed that the hydrogel and its degradation by-products are noncytotoxic. The evaluation of the applicability of $\mathrm{CH}$ in the treatment of dermal burns in Wistar rats was performed by induction of full-thickness transcutaneous dermal wounds. Wound healing was monitored through macroscopic and histological analysis. From macroscopic analysis, the wound beds of the animals treated with $\mathrm{CH}$ were considerably smaller than those of the controls. Histological analysis revealed lack of a reactive or a granulomatous inflammatory reaction in skin lesions with $\mathrm{CH}$ and the absence of pathological abnormalities in the organs obtained by necropsy, which supported the local and systemic histocompatibility of the biomaterial. The present results suggest that this biomaterial may aid the re-establishment of skin architecture.
\end{abstract}

Skin lesions are traumatic events that lead to the increase of fluid loss, hypothermia, scarring, locally immunocompromised regions, infections, and a change of body image. ${ }^{1}$ Despite advances in therapy, infections remain a leading cause of morbidity and mortality in burn patients. ${ }^{2}$

After skin damage, wound healing is a complex biological process, which includes a wide range of mechanisms, such as coagulation, inflammation, matrix synthesis and deposition, angiogenesis, fibroplasia, epithelialization, contraction, and remodeling. ${ }^{1,3}$ In spite of its complexity, regeneration of skin is often imperfect and the wound is mainly covered by scar tissue. ${ }^{4}$

The replacement of damaged tissues requires biocompatible materials on which cells may adhere and proliferate. Such materials include natural polymers extracted from the native extracellular matrix (ECM), like collagens and glycosaminoglycans. ${ }^{4}$ However, some of these materials, due to their chemical and biological inertness, may be unable to induce cell adhesion and proliferation. It is well known that adhesion and proliferation of cells to biomaterials is highly dependent on the topography of the substratum and its surface properties, namely its surface charge, surface free energy and density, along with the nature of its polar groups.,

In the past decades, many skin substitutes such as xenograft, allografts, and autografts have been used for the treatment of deep partial- and full-thickness wounds. However, due to the antigenicity or the limitation of do- nor sites, skin substitutes cannot accomplish the purpose of skin regeneration and hence are not widely used.?

Nowadays, none of the skin substitutes available or under development are able to fully substitute natural living skin. ${ }^{8}$

Chitosan is the deacetylated derivative of chitin, a natural polysaccharide found primarily in the exoskeletons of arthropods and some fungi. ${ }^{9}$ It is a linear polysaccharide comprising copolymers of glucosamine and $N$-acetyl glucosamine linked by $\beta(1-4)$ glycosidic bonds. The molar fraction of glucosamine residues is referred to as the degree of deacetylation (DD). ${ }^{10,11}$ In its crystalline form, chitosan is normally insoluble in an aqueous solution above $\mathrm{pH} 7$; however, in diluted acids $(\mathrm{pH} 6.0)$, the protonated free amino groups on glucosamine facilitate solubility of the molecule. Chitosan preparations of various molecular weights $(50-2,000 \mathrm{kDa})$, degrees of deacetylation (30$95 \%$ ), and further molecular derivatization patterns allow extensive adjustment of mechanical and biological

$\begin{array}{ll}\text { CH } & \text { Chitosan hydrogel } \\ \text { DD } & \text { Degree of deacetylation } \\ \text { DMEM-F12 } & \text { Dulbecco's modified Eagle's medium/Ham's F12 medium } \\ \text { ECM } & \text { Extracellular matrix } \\ \text { MTT } & \text { (3-[4,5-dimethyl-thiazol-2-yl]-2,5-diphenyltetrazolium } \\ & \text { bromide) }\end{array}$


properties. These properties include anticholesterolemic and antimicrobial activity, biocompatibility, biodegradability, fungistatic, hemostasis, noncarcinogenic, remarkable affinity to proteins, stimulation of healing, tissue engineering scaffolds, and drug delivery. ${ }^{2,3,12-15}$

Recently, there has been a growing interest in the chemical modification of chitosan in order to improve its solubility and widen its applications. ${ }^{16}$ Different studies have reported the use of chitosan for skin tissue engineering. ${ }^{13}$ Ueno et al. ${ }^{17}$ showed that chitosan in the form of chitosan-cotton accelerates wound healing by promoting infiltration of polymorphonuclear cells at the wound site. In recent studies, chitosan has been used to deliver bioactive molecules: basic fibroblast growth factor ${ }^{18}$ and human epidermal growth factor ${ }^{12}$ were encapsulated in this biomaterial; electrospun nonwoven nanofibrous hybrid mats based on chitosan and poly[(L-lactide)-co-(D,L-lactide)] were produced; ${ }^{19}$ chitosan dressing incorporating a procoagulant (polyphosphate) and an antimicrobial (silver) ${ }^{15}$ and chitosan acetate bandages were used as a topical antimicrobial dressing for infected burns. ${ }^{2}$

\section{MATERIALS AND METHODS}

\section{Hydrogel synthesis}

Chitosan (average $M_{\eta}=270,000 \mathrm{Da}$ and deacetylation degree $86 \%$ ) was obtained from Cognis (Monheim am Rhein, Germany). Lactic acid ( $>99.0 \%$ ) was purchased from HiMedia (Mumbai, India). Ammonium hydroxide solution at $25 \%$ (puriss. p.a.) was acquired from Fluka (Buch, Switzerland).

The chitosan hydrogel $(\mathrm{CH})$ was produced adapting the method described previously by Montembault et al. ${ }^{11}$ Briefly, to prepare the $\mathrm{CH}$, a chitosan solution $4 \%(\mathrm{w} / \mathrm{w})$ was dispersed in lactic acid $2 \%(\mathrm{v} / \mathrm{v})$ to achieve the stoichiometric protonation of the $-\mathrm{NH}_{2}$ sites, followed by agitation until complete dissolution. The solution was left overnight in order for the air bubbles to collapse completely. Chitosan solution was poured into several small molds $(14 \times 7 \mathrm{~cm}), 30 \mathrm{~g}$ per mold. The molds were placed inside a hermetic chamber, together with $4 \mathrm{~L}$ of ammonia solution, $2.5 \%(\mathrm{v} / \mathrm{v})$. The chitosan solutions were left exposed to ammonia vapor overnight. The hydrogels were rinsed with distilled water, removed from the molds, and placed in watch glasses for 5 hours in order for the excess ammonia to evaporate. The prepared $\mathrm{CH}$ was packed separately and sealed in plastic bags. The samples were labeled and sterilized by UV radiation for 30 minutes. The packed, sterilized $\mathrm{CH}$ was then maintained at room temperature in a dry and clean place until use.

\section{Scanning electron microscopy}

The morphologies of $\mathrm{CH}$ with/without adhered fibroblasts cells isolated from rat skin were characterized by scanning electron microscopy (SEM). $\mathrm{CH}$ and their adherent fibroblasts were fixed overnight with $2.5 \%$ glutaraldehyde in phosphate-buffered saline (PBS) at $4{ }^{\circ} \mathrm{C}$. Samples were rinsed three times with PBS buffer for 2 minutes and dehydrated in graded ethanol (ETOH) of 70, 80, 90, and $100 \%, 5$ minutes each. Then, hydrogels were mounted on an aluminum board using a double-sided adhesive tape and sputter coated with gold using an Emitech K550 (London, England) sputter coater. The samples were analyzed using a Hitachi S-2700 (Tokyo, Japan) scanning electron microscope operated at an accelerating voltage of $20 \mathrm{kV}$ at various magnifications.

\section{Cell source and growth}

Fibroblast cells from rat skin were obtained as reported previously. ${ }^{20}$ The operative skin area was shaved and disinfected using 70\% ETOH. Skin samples were aseptically removed from the rats and stored in RPMI-1640 (Gibco, Grand Island, NY) medium with penicillin G (100 U/mL), streptomycin $(100 \mu \mathrm{g} / \mathrm{mL})$, and amphotericin B $(0.25 \mu \mathrm{g} /$ $\mathrm{mL})$. Then, the samples were minced and incubated for 3 hours in $0.1 \%$ collagenase solution $\left(37^{\circ} \mathrm{C}, 5 \% \mathrm{CO}_{2}\right)$. After incubation, the samples were centrifuged $(5$ minutes, $250 \times g$ ), the supernatant was discarded, and the pellet was washed with Dulbecco's modified Eagle's medium (DMEM)-F12 supplemented with heat-inactivated fetal bovine serum (FBS, $10 \% \mathrm{v} / \mathrm{v})$. The isolated cells were plated in $25 \mathrm{~cm}^{3}$ T-flasks with DMEM-F12 medium (1:1 $\mathrm{v} / \mathrm{v})$ supplemented with heat-inactivated FBS $(10 \% \mathrm{v} / \mathrm{v})$, L-glutamine $(2 \mathrm{mM})$, penicillin $\mathrm{G}(100 \mathrm{U} / \mathrm{mL})$, streptomy$\operatorname{cin}(100 \mu \mathrm{g} / \mathrm{mL})$, and amphotericin B $(0.25 \mu \mathrm{g} / \mathrm{mL})$.

After 2 hours, the nonadherent cells were washed out. Cells were kept in culture at $37^{\circ} \mathrm{C}$, in a humidified atmosphere, $5 \% \mathrm{CO}_{2}$. After confluence was attained, cells were subcultivated by a 5 -minute incubation in $0.18 \%$ trypsin $(1: 250)$ and $5 \mathrm{mM}$ EDTA. The free cells were added to an equal volume of culture medium. Following centrifugation, cells were resuspended in sufficient culture medium.

\section{Proliferation of fibroblast cells in the presence of $\mathrm{CH}$}

To examine cell proliferation, fibroblast cells were cultured in 24-well plates at $1 \times 10^{5}$ cells $/ \mathrm{mL}$ for 24 hours. Cell growth was monitored using an Olympus CX41 (Tokyo, Japan) inverted light microscope equipped with an Olympus SP-500 UZ digital camera and SEM images were also acquired.

\section{Determination of hydrogel cytotoxicity by 3-[4,5- dimethyl-thiazol-2-yl]-2,5-diphenyltetrazolium bromide (MTT) assay}

$\mathrm{CH}$ was applied to a 96-well plate (Nunc, Roskilde, Denmark). The plates were UV irradiated for 30 minutes, before cell seeding.

Second passage rat fibroblasts cells were seeded in a 96well plate containing the biomaterial at a density of $6 \times 10^{4}$ cells per well. Then, $100 \mu \mathrm{L}$ of culture medium was added to each well and the plate was incubated at $37^{\circ} \mathrm{C}$, in a $5 \%$ $\mathrm{CO}_{2}$ humidified atmosphere, for 24 hours. After incubation, the mitochondrial redox activity was assessed through the reduction of the MTT $(n=6)$. Fifty microliters of MTT $(5 \mathrm{mg} / \mathrm{mL}$ PBS) was added to each sample, followed by incubation for 4 hours at $37{ }^{\circ} \mathrm{C}$, in a $5 \% \mathrm{CO}_{2}$ atmosphere. The medium was aspirated and cells were treated with $50 \mu \mathrm{L}$ of isopropanol $/ \mathrm{HCl}(0.04 \mathrm{~N})$ for 90 
minutes. Absorbance at $570 \mathrm{~nm}$ was measured using a Biorad Microplate Reader Benchmark (Tokyo, Japan).

Wells containing cells in the culture medium without biomaterials were used as negative control. ETOH 96\% was added to wells containing cells as a positive control.

\section{Animal experiments}

A total of 18 female Wistar rats (8-10 weeks) were used, weighing between 200 and $250 \mathrm{~g}$ at the time of the experiments. The animal protocols followed in the present study were approved by the Ethics Committee of Centro Hospitalar Cova da Beira and were performed according to the guidelines set forth in the National Institutes of Health Guide for the care and use of laboratory animals.

Rats were individually anesthetized via an IP injection (40 mg/kg ketamine, $5 \mathrm{mg} / \mathrm{kg}$ xylazine) for surgery and induction of the burn wound. The operative skin area was shaved and disinfected using ETOH. Then, the dorsal skin of the animal was exposed to water at $95 \pm 1{ }^{\circ} \mathrm{C}$ for $10 \mathrm{sec}-$ onds. After 2 hours, damaged tissue was removed with surgical scissors and forceps. Wounds of $2 \mathrm{~cm}$ diameter were created with no visible bleeding. The animals were divided into two groups: in group 1, wounds were filled with $\mathrm{CH}$ and finally fixed with elastic bandage; group 2 was used as control and wounds were covered with PBS and an elastic bandage.

After surgery, animals were kept in separate cages and were fed with commercial rat food and water ad libitum. All animals showed good general health condition throughout the study, as assessed by their weight gain. The animals were sacrificed after 7, 14, and 21 days.

\section{Histological study}

The material from the skin lesions and organs (brain, heart, lung, liver, spleen, and kidney) obtained by necropsy was formalin fixed and paraffin embedded for routine histological processing. A $3 \mu \mathrm{m}$ section obtained from each paraffin block was stained with hematoxylin and eo$\sin (\mathrm{H} \& \mathrm{E})$ and evaluated in a blinded manner by two observers using a light microscope with specific image analysis software from Olympus. For the morphological evaluation of skin lesions, three parameters were considered: wound bed length, thickness of the granulation tissue layer, and thickness of the epithelial layer. In the assessment of the three parameters it was always considered the greatest dimension observed. Skin fragments with no $\mathrm{CH}$ were used as normal control. The assessment of the brain, heart, liver, lung, kidney, and spleen was performed by looking for any morphological alteration.

\section{Evaluation of the wound size}

Images of the wound area were taken by a digital camera (Nikon D50, Ayuthaya, Thailand) and analyzed with image analysis software Image J (Scion Corp., Frederick, MD). Measurement of the wound closure area was defined by the limits of grossly evident epithelialization, with all surface areas in a two-dimensional plane calibrated against the adjacent metric ruler. The percentage of wound size was calculated using the following formula: $D_{\mathrm{N}} / D_{0} \times$ $100(\%)$, where $D_{0}$ is the dimension of the full-thickness circular skin wound area $\left(2 \mathrm{~cm}\right.$ diameter) on day 0 and $D_{\mathrm{N}}$ is the dimension of the wound area on the indicated day.
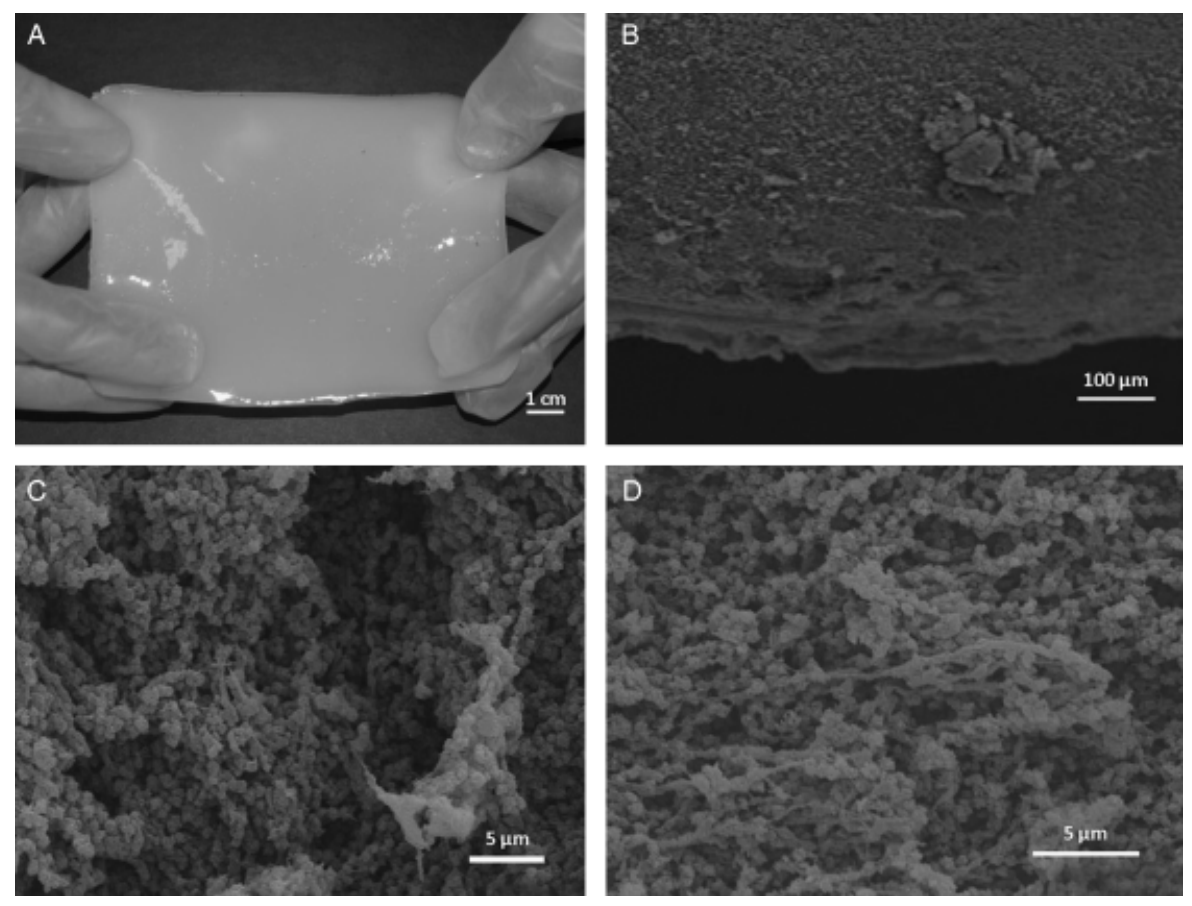

Figure 1. Photograph of chitosan hydrogel $(\mathrm{CH})(\mathrm{A})$ and scanning electron microscopic images of $\mathrm{CH}$ surface morphology (B-D). Original magnification: (A) scale bar $1 \mathrm{~cm}$; $(B)$ $\times 50$, scale bar $100 \mu \mathrm{m}$; (C) $\times 2,000$, scale bar $5 \mu \mathrm{m}$; (D) $\times 3,000$, scale bar $5 \mu \mathrm{m}$. 

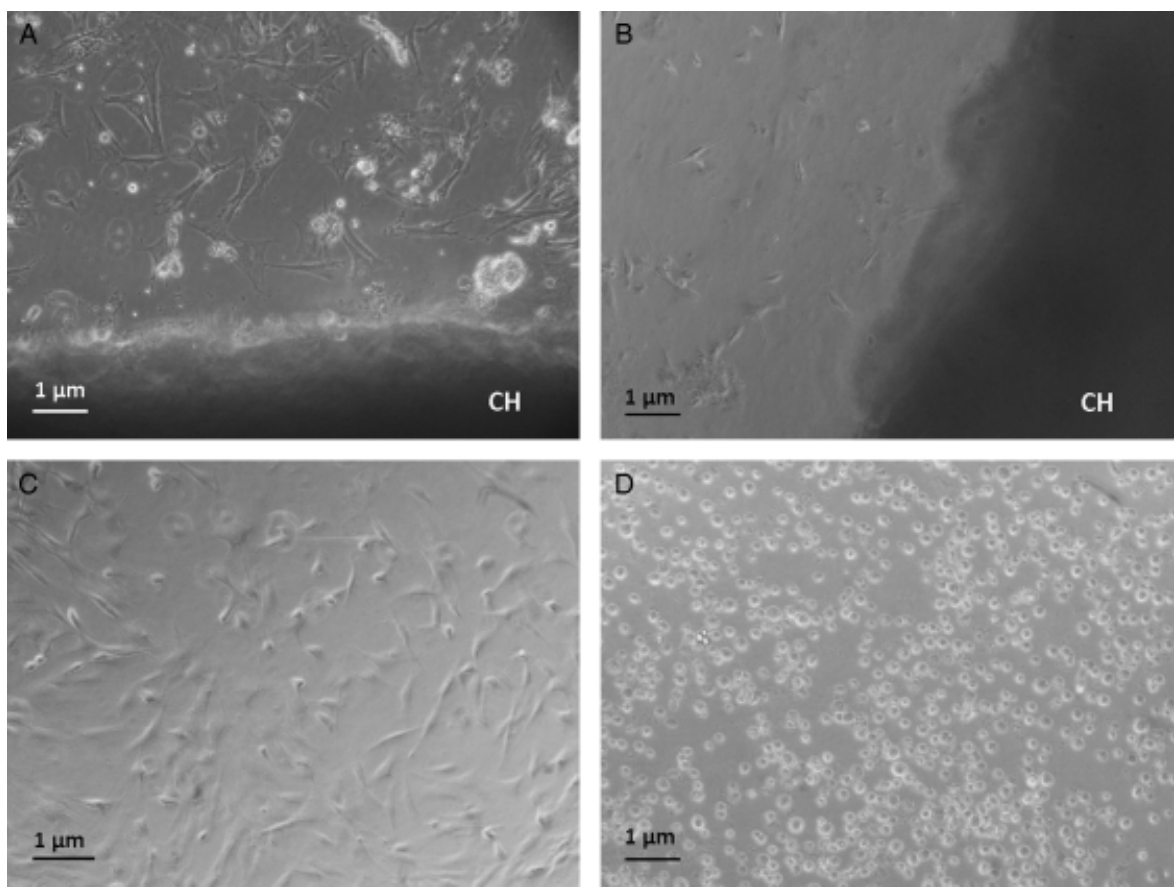

Figure 2. Photomicrographs of fibroblast cells from rat skin after being seeded on chitosan hydrogel $(\mathrm{CH})$ after 24 hours $(A)$ and 3 days $(B)$; polystyrene $(\mathrm{C})$; and polystyrene with ethanol 96\% (D). Original magnification $\times 100$, scale bar $1 \mu \mathrm{m}$.

\section{Statistical analysis}

In each measurement of the surface area of the burn wounds, a minimum of three animals were used. The results obtained were expressed as mean \pm standard error of the mean. Differences between groups were tested by one-way ANOVA with Dunnet's post hoc test. Computations were performed using a MYSTAT 12 statistical package (Systat Software, a subsidiary of Cranes Software International Ltd.).

\section{RESULTS}

\section{Morphology of CH}

From gross observation, the $\mathrm{CH}$ was white, opaque, and presented a dense outer layer, as shown in Figure 1A. The dense outer layer of hydrogel provides several functions such as control of the water loss through evaporation and protection from external contamination, as reported previously in the literature. ${ }^{12}$
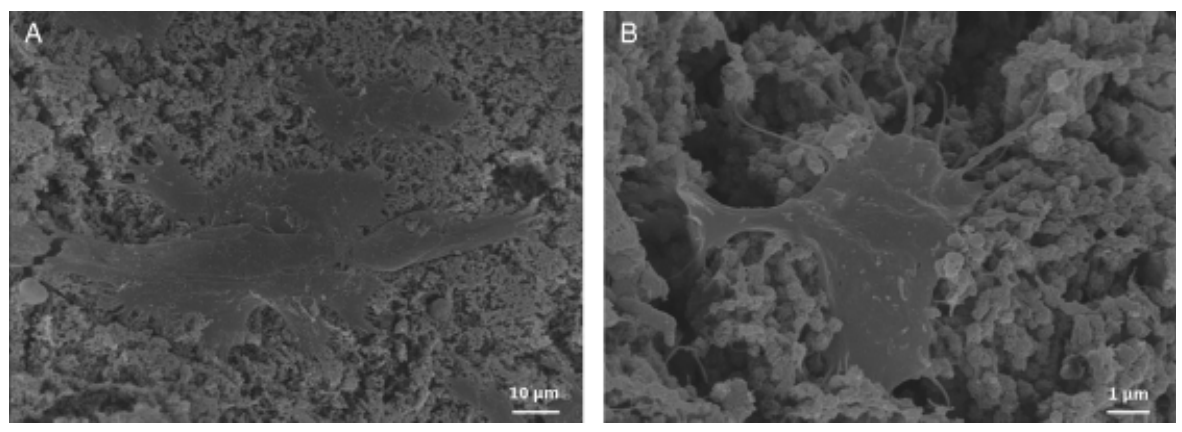

SEM analysis (Figure 1B-D) revealed a highly porous and interconnected interior structure. It could be inferred that the hydrogel has a high water-retention capacity because high DD chitosan (86\%) can establish H-bonds with water. Both small and macromolecules could freely diffuse into $\mathrm{CH}$.

\section{Cytotoxicity of $\mathbf{C H}$}

In order to study the applicability of our new hydrogel for biomedical applications, the cytocompatibility of $\mathrm{CH}$ was first studied through in vitro studies. Fibroblasts were seeded at the same initial density in the 96-well plates, with or without hydrogel, on day 0 , to assess the $\mathrm{CH}$ cytoxicity. After 24 hours, cell adhesion and proliferation was visualized using an inverted light microscope (Figure 2). Fibroblast cells adhere and grow in the vicinity of $\mathrm{CH}$ (Figure $2 \mathrm{~A}$ and $\mathrm{B}$ ) and in the negative control (Figure 2C). In the positive control, no cell adhesion or proliferation was observed. Dead cells with their typical spherical shape can be observed in Figure 2D. 


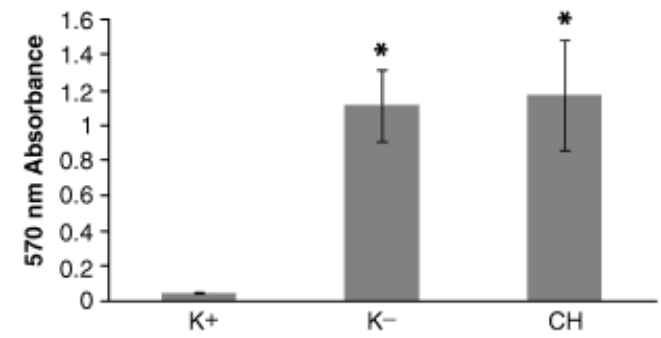

Figure 4. Cellular activities measured by the 3-[4,5-dimethylthiazol-2-yl]-2,5-diphenyltetrazolium bromide assay. $\mathrm{K}+$, positive control; $\mathrm{K}-$, negative control; $\mathrm{CH}$, chitosan hydrogel. Fibroblast cells in the presence of biomaterial. Each result is the mean \pm standard error of the mean of at least three independent experiments. Statistical analysis was performed using one-way ANOVA with Dunnet's post hoc test $(* p<0.05)$.

SEM images were acquired to further examine and characterize cell adhesion to $\mathrm{CH}$. Cell growth and filopodia were observed, indicating that cells were attached and spread on hydrogels after 24 hours (Figure 3A) and 7 days (Figure 3B). Because of their large volume, the fibroblasts could not penetrate into the pore cavity and remained on the surface of $\mathrm{CH}$. Fibroblasts synthesize and organize an ECM, which is fundamental for the repair of the lesion and avoid formation of hypertrophic scars and keloids. ${ }^{4}$

To further evaluate the biocompatibility of the $\mathrm{CH}$, an MTT assay was also performed (Figure 4). The MTT assay showed a significant difference between cells exposed to $\mathrm{CH}$ and the positive control $(p<0.05)$ after 24 hours of incubation, suggesting that the hydrogel did not affect cell viability. These results show that the tested formulation does not have an acute cytotoxic effect.

\section{Acceleration of wound healing by $\mathrm{CH}$ in rats transcutaneous full-thickness dermal wounds}

In vivo experiments showed that $\mathrm{CH}$ adhered uniformly to the freshly excised wound surface, as reported previously in the literature. ${ }^{21}$ In the inflammatory phase, chitosan has unique hemostatic properties that are independent of the normal coagulation cascade. ${ }^{3,22}$

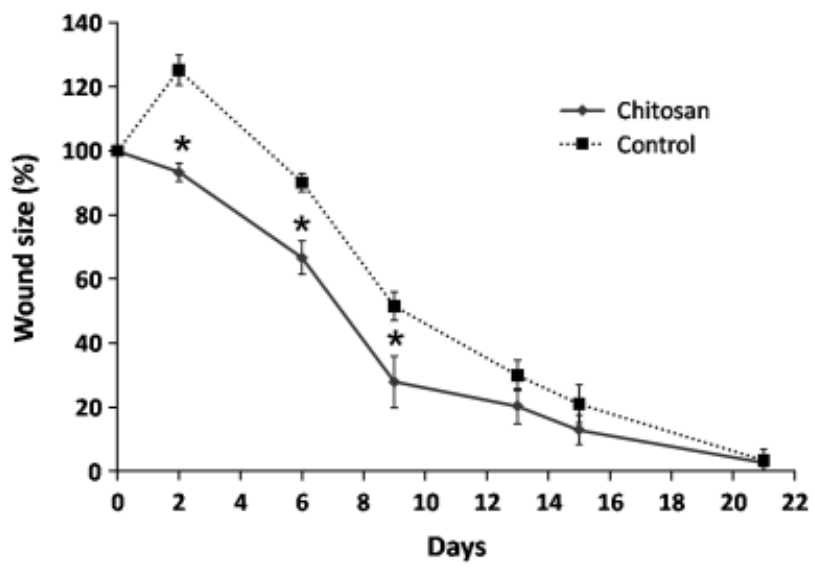

Figure 6. Effect of chitosan hydrogel and phosphate-buffered saline on burn wound. The surface area of the burn wounds was calculated as described in methods and reported at each time point as the percentage of the surface area at baseline. Each point represents the mean \pm standard error of the mean of at least three independent experiments. *Chitosan vs. control ( $p<0.05$, one-way ANOVA with Dunnet's post-hoc test).

Figure 5 shows a set of typical wound beds shortly after the surgical procedure and application of the hydrogel. The healing patterns were observed after $2,6,9,13,15$, and 21 days and showed that the topical application of chitosan improved wound healing. The wound area decreased rapidly in the presence of hydrogel when compared with the control (Figures 5 and 6). The results obtained were statistically significant until day 9 .

\section{Histological study}

The results of the histological study are summarized in Figure 7. The analysis of histological data (Figure 8) showed that the maximum and minimum values for wound bed length and granulation tissue thickness were obtained on days 14 and 21, respectively. Epithelial layer thickness increased progressively from days 7 to 21. On day 21, all the skin lesions exhibited complete epithelialization. Neither specific inflammation nor reactive granulomas to the presence of $\mathrm{CH}$ were observed. No
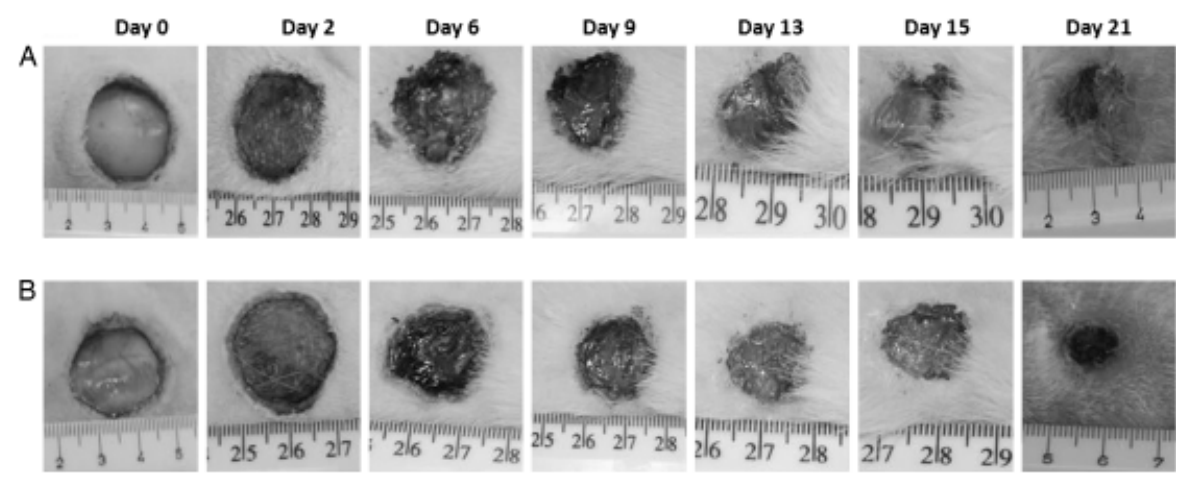
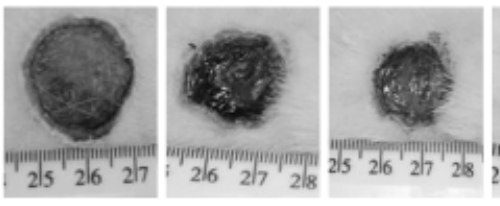
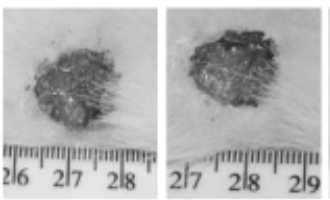

Figure 5. Typical macroscopic woundhealing panorama with different treatments over 21 days. One deep thirddegree burn wound with $2 \mathrm{~cm}$ diameter at the dorsal skin of female Wistar rats, treated with chitosan hydrogel (A) and phosphate-buffered saline. (B). All went through various healing phases such as inflammation, eschar, tissue formation and tissue remodeling on the 2nd, 6th, 9th, 13th, 15th, and 21st day after injury. 


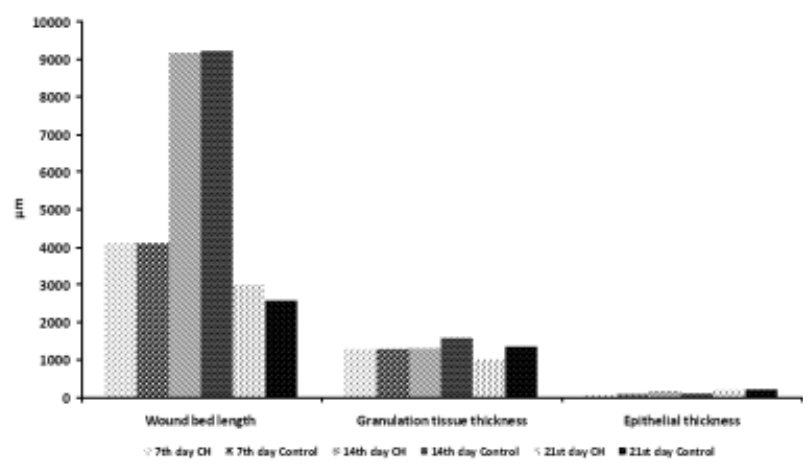

Figure 7. Graph with results of the histological analysis. For the morphological evaluation of skin lesions, three parameters were considered: wound bed length, thickness of the granulation tissue layer, and thickness of the epithelial layer. Skin fragments with no chitosan hydrogel $(\mathrm{CH})$ were used as control.

microorganisms were observed in skin lesions. No pathological abnormalities were observed in the brain, heart, liver, lung, kidney, and spleen obtained during necropsy.

\section{DISCUSSION}

Wound healing is a dynamic process that typically evolves from its initial inflammatory response to complete resolution and thus, healing. ${ }^{23}$ Hydrogels, with their high water contents and retention capacity, appear to be optimal media to enhance wound healing, ${ }^{23,24}$ and thus, considerable interest has been focused on developing hydrogel-based wound dressings from biomaterials. ${ }^{23,25}$

In the present work, a $\mathrm{CH}$ was prepared through a recent development of the method described previously in the literature. ${ }^{11}$ Chitosan is considered as an appropriate functional material for biomedical applications because of high biocompatibility, biodegradability, nonantigenicity, and adsorption properties. Anti-inflammatory or allergic reactions have not been observed in human subjects following topical application, implantation, injection, and ingestion. $^{26}$ In previous studies, Montembault et al. ${ }^{11}$ reported that the percentage of DD and polymer concentration influences the mechanism of gelation of $\mathrm{CH}$. For high DD, the high charge density is responsible for strong electrostatic repulsions, which do not favor the formation of physical junctions between chain segments. The present hydrogel was mainly built by hydrogen bonding. In high concentrated polymer solutions, chains become entangled, and hydrogel forms rapidly. ${ }^{27}$ Lactic acid was added to induce the stoichiometric protonation of the $-\mathrm{NH}_{2}$ sites.

Keeping in mind the wound dressing application, the porous section of $\mathrm{CH}$ (Figure 1) promotes drainage, prevents the build-up of exudates, and may be an optimum wound bed for autografting. Moreover, the porosity of $\mathrm{CH}$ promotes gas exchange, which is fundamental for the wound-healing process. A high $\mathrm{CO}_{2}$ pressure increases the acidity and slows down the healing process, and in addition, a low oxygen concentration decreases the regeneration of tissue cell or facilitates the proliferation of anaerobic bacteria. $^{22}$ Our $\mathrm{CH}$ appears to be particularly interesting for the proposed biomedical application, because it behaves as a decoy of biological media, both due to its physical form and its chemical structure. Indeed, the $\beta(1-4)$ glycosidic linkage and the $N$-acetyl groups are present in the structure of extra-cellular matrixes. ${ }^{27}$

The observation of cell growth in the presence of $\mathrm{CH}$ (Figures 2 and 3 ) revealed the importance of the method used to obtain the present hydrogel, because previous studies reported that there is no evidence that chitosan ${ }^{28}$ or chitosan-coated membranes ${ }^{4}$ can support adhesion and proliferation of fibroblasts in vitro. It is well known that the surface chemistry of hydrogels can affect cell adhesion, proliferation, and other phenomena. ${ }^{6}$ Chitosan used to produce $\mathrm{CH}$ presents a DD of $86 \%$, which is responsible for $\mathrm{CH}$ being positively charged at the surface. Hamilton et al. ${ }^{29}$ reported that increased $N$-acetylation of chitosan changes the physical properties of chitosan, as it becomes less positively charged and more hydrophobic. The high DD of $\mathrm{CH}$ allows electrostatic interactions of cationic $\mathrm{NH}_{3}^{+}$groups with anionic glycosaminoglycans, proteoglycans, and other negatively charged molecules that are present in the cell membranes. ${ }^{30}$ Because skin has a negative charge and $\mathrm{CH}$ is a cation polymer, it can bind electrostatically to the skin, as reported previously in the literature. ${ }^{31}$ These electrostatic interactions are fundamental for the suitability of the material for the function proposed herein.

In vitro and in vivo cytocompatibility studies revealed that $\mathrm{CH}$ and its degradation by-products are biocompatible, suggesting that $\mathrm{CH}$ has no cytotoxic effect.
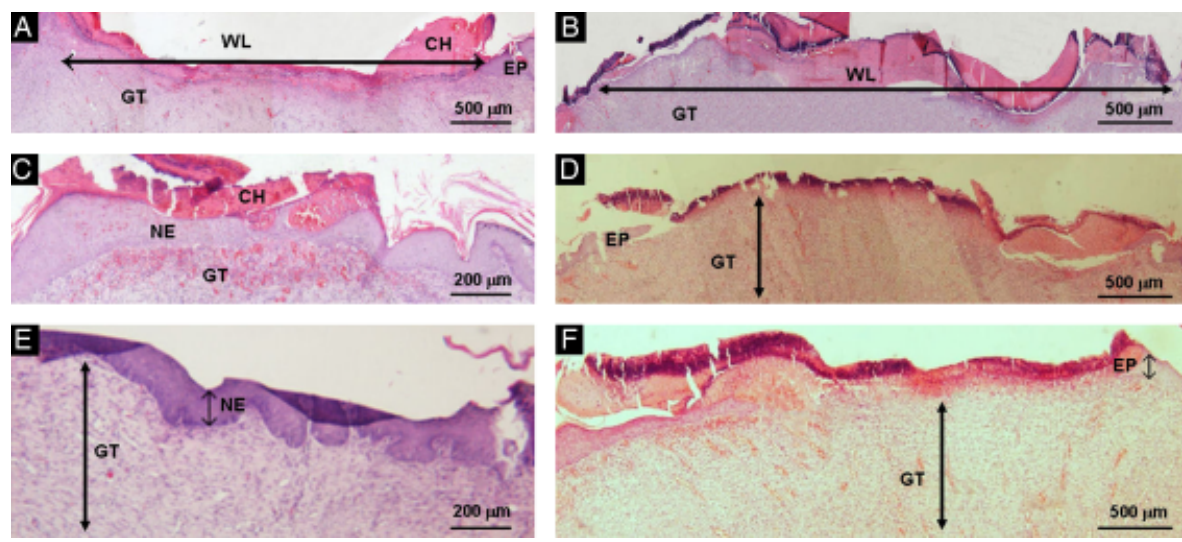

Figure 8. Hematoxylin and eosinstained sections of biopsies for the morphological evaluation of skin lesions. $\mathrm{CH}$-treated wound on the 7th day, scale bar $500 \mu \mathrm{m}$ (A), at 14 th day, scale bar $200 \mu \mathrm{m}(\mathrm{C})$, and at 21 st day, scale bar $200 \mu \mathrm{m}$ (E). Control wound on the 7 th day $(B)$, on the 14 th day (D), and on the 21 st day (F), scale bar $500 \mu \mathrm{m}$. $\mathrm{CH}$, chitosan hydrogel, EP, epithelial layer, GT, granulation tissue, NE, new epithelial layer; WL, wound length. 
From macroscopic analysis, the wound beds of the animals treated with $\mathrm{CH}$ were considerably smaller as compared with those of the controls treated with PBS. Macroscopic findings did not reveal a significant difference in terms of the wound contraction area after day 9.

The wound area of the control animals increased during the first days (Figure 6), which was not observed in the animals treated with $\mathrm{CH}$. Therefore, this supports the promoting role of $\mathrm{CH}$ in wound healing. These results corroborate what has been reported previously in the literature. ${ }^{32-34}$

In the histological study, the lack of a reactive or a granulomatous inflammatory reaction in skin lesions with $\mathrm{CH}$ and the absence of pathological abnormalities in the organs obtained by necropsy supported the local and systemic histocompatibility of the biomaterial. Furthermore, the increasing thickness of the epithelial layer during the experiment and the presence of complete epithelialization in all the skin samples treated by $\mathrm{CH}$ suggest that this biomaterial may aid the re-establishment of tissue architecture. In addition, the absence of microorganisms in skin lesions, after $\mathrm{CH}$ treatment, supports the previously described antimicrobial properties of $\mathrm{CH}^{2}$ and supports its role in skin repair.

Further studies will be required to clarify the clinical significance of these findings for wound healing. The addition of grafted dermal fibroblasts to this natural polymer may aid the remodeling of wounds and their perfect healing, as demonstrated for a number of skin substitutes.

\section{ACKNOWLEDGMENTS}

The authors would like to thank Ana Paula Gomes for acquiring SEM images and Ricardo Relvas for his technical support in the preparation of the final images for publication. Funding was provided by the Portuguese Foundation for Science and Technology (in the form of a fellowship to $\mathrm{AE}-\mathrm{SFRH} / \mathrm{BDE} / 15653 / 2007$ and IJC-SFRH/BPD/ 19776/2004).

\section{REFERENCES}

1. Alemdaroglu C, Degim Z, Celebi N, Zor F, Ozturk S, Erdogan D. An investigation on burn wound healing in rats with chitosan gel formulation containing epidermal growth factor. Burns 2006; 32: 319-27.

2. Dai T, Tegos GP, Burkatovskaya M, Castano AP, Hamblin MR. Chitosan acetate bandage as a topical antimicrobial dressing for infected burns. Antimicrob Agents Chemother 2009; 53(2): 393-400.

3. Kim IY, Seo SJ, Moon HS, Yoo MK, Park IY, Kim BC, Cho CS. Chitosan and its derivatives for tissue engineering applications. Biotechnol Adv 2008; 26: 1-21.

4. Attia J, Legendre F, Nguyen QT, Bauge C, Boumediene K, Pujol JP. Evaluation of adhesion, proliferation, and functional differentiation of dermal fibroblasts on glycosaminoglycan-coated polysulfone membranes. Tissue Eng Part A 2008; 14: 1687-97.

5. Zeltinger J, Sherwood JK, Graham DA, Mueller R, Griffith LG. Effect of pore size and void fraction on cellular adhe- sion, proliferation, and matrix deposition. Tissue Eng 2001; 7: $557-72$

6. Chen YM, Shiraishi N, Satokawa H, Kakugo A, Narita T, Gong JP, Osada Y, Yamamoto K, Ando J. Cultivation of endothelial cells on adhesive protein-free synthetic polymer gels. Biomaterials 2005; 26: 4588-96.

7. Ma L, Gao C, Mao Z, Zhou J, Shen J, Hu X, Han C. Collagen/chitosan porous scaffolds with improved biostability for skin tissue engineering. Biomaterials 2003; 24: 4833-41.

8. Metcalfe AD, Ferguson MW. Bioengineering skin using mechanisms of regeneration and repair. Biomaterials 2007; 28: 5100-13.

9. Montembault A, Viton C, Domard A. Physico-chemical studies of the gelation of chitosan in a hydroalcoholic medium. Biomaterials 2005; 26: 933-43.

10. Lavertu M, Xia Z, Serreqi AN, Berrada M, Rodrigues A, Wang D, Buschmann MD, Gupta A. A validated $1 \mathrm{H}$ NMR method for the determination of the degree of deacetylation of chitosan. J Pharm Biomed Anal 2003; 32: 1149-58.

11. Montembault A, Viton C, Domard A. Rheometric study of the gelation of chitosan in aqueous solution without crosslinking agent. Biomacromolecules 2005; 6: 653-62.

12. Hong JP, Kim YW, Lee SK, Kim SH, Min KH. The effect of continuous release of recombinant human epidermal growth factor (rh-EGF) in chitosan film on full thickness excisional porcine wounds. Ann Plast Surg 2008; 61: 457-62.

13. Boateng JS, Matthews KH, Stevens HN, Eccleston GM. Wound healing dressings and drug delivery systems: a review. J Pharm Sci 2008; 97: 2892-923.

14. VandeVord PJ, Matthew HW, DeSilva SP, Mayton L, Wu B, Wooley PH. Evaluation of the biocompatibility of a chitosan scaffold in mice. J Biomed Mater Res 2002; 59: 585-90.

15. Ong SY, Wu J, Moochhala SM, Tan MH, Lu J. Development of a chitosan-based wound dressing with improved hemostatic and antimicrobial properties. Biomaterials 2008; 29: 4323-32.

16. Alves NM, Mano JF. Chitosan derivatives obtained by chemical modifications for biomedical and environmental applications. Int J Biol Macromol 2008; 43: 401-14.

17. Ueno H, Yamada H, Tanaka I, Kaba N, Matsuura M, Okumura M, Kadosawa T, Fujinaga T. Accelerating effects of chitosan for healing at early phase of experimental open wound in dogs. Biomaterials 1999; 20: 1407-14.

18. Mizuno K, Yamamura K, Yano K, Osada T, Saeki S, Takimoto N, Sakurai T, Nimura Y. Effect of chitosan film containing basic fibroblast growth factor on wound healing in genetically diabetic mice. J Biomed Mater Res A 2003; 64: 177-81.

19. Ignatova M, Manolova N, Markova N, Rashkov I. Electrospun non-woven nanofibrous hybrid mats based on chitosan and PLA for wound-dressing applications. Macromol Biosci 2009; 9: 102-11.

20. Blasinska A, Drobnik J. Effects of nonwoven mats of Di-Obutyrylchitin and related polymers on the process of wound healing. Biomacromolecules 2008; 9: 776-82.

21. Azad AK, Sermsintham N, Chandrkrachang S, Stevens WF. Chitosan membrane as a wound-healing dressing: characterization and clinical application. J Biomed Mater Res B Appl Biomater 2004; 69: 216-22.

22. Mi FL, Shyu SS, Wu YB, Lee ST, Shyong JY, Huang RN. Fabrication and characterization of a sponge-like asymmetric chitosan membrane as a wound dressing. Biomaterials 2001; 22: 165-73. 
23. Weng L, Romanov A, Rooney J, Chen W. Non-cytotoxic, in situ gelable hydrogels composed of N-carboxyethyl chitosan and oxidized dextran. Biomaterials 2008; 29: 3905-13.

24. Balakrishnan B, Mohanty M, Umashankar PR, Jayakrishnan A. Evaluation of an in situ forming hydrogel wound dressing based on oxidized alginate and gelatin. Biomaterials 2005; 26: 6335-42.

25. Garcia Y, Wilkins B, Collighan RJ, Griffin M, Pandit A. Towards development of a dermal rudiment for enhanced wound healing response. Biomaterials 2008; 29: 857-68.

26. Thein-Han WW, Misra RD. Biomimetic chitosan-nanohydroxyapatite composite scaffolds for bone tissue engineering. Acta Biomater 2009; 5: 1182-97.

27. Montembault A, Viton C, Domard A. Rheometric study of the gelation of chitosan in a hydroalcoholic medium. Biomaterials 2005; 26: 1633-43.

28. Mori T, Okumura M, Matsuura M, Ueno K, Tokura S, Okamoto Y, Minami S, Fujinaga T. Effects of chitin and its derivatives on the proliferation and cytokine production of fibroblasts in vitro. Biomaterials 1997; 18: 947-51.

29. Hamilton V, Yuan Y, Rigney DA, Puckett AD, Ong JL, Yang Y, Elder SH, Bumgardner JD. Characterization of chitosan films and effects on fibroblast cell attachment and proliferation. J Mater Sci Mater Med 2006; 17: 1373-81.

30. Liu H, Du Y, Wang X, Sun L. Chitosan kills bacteria through cell membrane damage. Int J Food Microbiol 2004; 95: $147-55$.

31. Hong HJ, Jin SE, Park JS, Ahn WS, Kim CK. Accelerated wound healing by smad 3 antisense oligonucleotides-impregnated chitosan/alginate polyelectrolyte complex. Biomaterials 2008; 29: 4831-7.

32. Galiano RD, Michaels J, Dobryansky M, Levine JP, Gurtner GC. Quantitative and reproducible murine model of excisional wound healing. Wound Repair Regen 2004; 12: 485-92.

33. Kiyozumi T, Kanatani Y, Ishihara M, Saitoh D, Shimizu J, Yura H, Suzuki S, Okada Y, Kikuchi M. Medium (DMEM/F12)-containing chitosan hydrogel as adhesive and dressing in autologous skin grafts and accelerator in the healing process. J Biomed Mater Res B Appl Biomater 2006; 79: 129-36.

34. Kimura Y, Sumiyoshi M, Samukawa K, Satake N, Sakanaka M. Facilitating action of asiaticoside at low doses on burn wound repair and its mechanism. Eur J Pharmacol 2008; 584: 415-23. 